\title{
Physical fitness of individuals with intellectual disability who have Special Olympics experience
}

\author{
Pauli Rintala ${ }^{1}$, Piritta Asunta ${ }^{1}$, Jukka Lahti ${ }^{1}$, and Edwin Michael Loovis ${ }^{2}$ \\ ${ }^{1}$ University of Jyväskylä, Finland; and ${ }^{2}$ Cleveland State University, Ohio, United States of America
}

\begin{abstract}
Physical fitness of individuals with intellectual disability (ID) is low compared to those without ID. Part of the mission of Special Olympics is to develop physical fitness. However, little is known about fitness levels of Special Olympics athletes. This study examined the fitness level of individuals who participated in Nordic Special Olympics Games 2008 in Finland. The sample consisted of 59 Special Olympics athletes (44 men, 15 women, age 16-45) whose fitness scores were compared to INAS-athletes (International Association of Sport for para-athletes with ID) and Finnish non-athletic individuals with ID. The fitness battery consisted of 8 items: BMI, sit-and-reach test, stork stand, sit up, standing long jump, hand grip, shuttle run, and $1 \mathrm{mile} / 2 \mathrm{~km}$ walk test. BMI values were in the range of the nondisabled population. All other fitness values were below the means of the INAS-athletes, but above the Finnish non-athletes. Based on this data which is supported by the existing literature, the level of fitness of Special Olympics athletes needs further scrutiny. Given that the participants were Special Olympics athletes, who trained regularly, the low fitness level is alarming. Therefore, a closer examination of the contents of physical fitness training programs in Special Olympics is warranted.
\end{abstract}

Keywords: Special Olympics athlete, training, adults

\section{Introduction}

Physical fitness and regular physical activity are key factors in health and wellbeing of all individuals, including those with an intellectual disability (ID) (Lorentzen \& Wikström, 2012). Physical fitness in most definitions includes the following components: body composition, cardiorespiratory capacity, muscle strength and endurance, balance and flexibility. These components are essential for independent living and for developing functional skills (Cowley et al., 2010; Rimmer, 2000).

People with ID have sedentary lifestyles more often than people without disability. A sedentary lifestyle that results from inadequate levels of physical fitness can contribute to numerous health problems, including obesity, hypertension, low back pain, coronary heart disease, osteoporosis, diabetes, and premature mortality (Evenhuis, Henderson, Beange, Lennox, \& Chicoine, 2000; Foster, Walkley, \& Temple, 2001). People have their own individual fitness needs, and physical fitness is as important for the adult with ID as it is for those without ID. However, the fitness levels of persons with ID are generally lower in comparison to general population (Graham \& Reid, 2000; Lahtinen, Rintala, \& Malin, 2007). Several predictors of lower physical activity in populations of individuals with ID compared to the general population have been identified: these include older age, immobility, seizure disorder, lack of opportunity to exercise during the day, living in congregate care, and bowel and bladder incontinence (Finlayson et al., 2009). Other factors that appear to mediate against participation include BMI (McGuire, Daly, \& Smyth, 2007) and lack of choices and support for participation in daily physical activity (Messent, Cooke, \& Long, 1998; Temple \& Walkley, 2007).

Participation in regular physical activity is important to maintain adequate fitness level, vocational productivity, and optimal health. Functional training regimes have produced significant results in children and adolescents as measured by various assessment measures from the Brockport Physical Fitness Test (Barwick et al., 2012). Individuals with ID need systematic intervention strategies for building their physical fitness, but they are not always self-directed enough to learn about the opportunities to engage in physical activity.

Moreover, motivation not only to initiate and but also to sustain training is often lacking. Generally speaking, the state of intervention research related to improved participation in physical activity by adults with ID is at best negligible, especially in light of significant research with non-ID adults (Brooker, van Dooren, McPherson, Lennox \& Ware, 2015). 
Special Olympics provides year-round sports training opportunities in many countries for children and adults with ID. As it relates to older Special Olympians, Gillespie (2008) identified several significant areas of concern relative to participation patterns. He described a population of participants who were predominantly male, older than the typical participant from other sport organizations, and with fewer choices of sports. Regular participation in Special Olympics programs will affect their physical fitness levels and may help in their adjustment into manual job opportunities.

On the other hand, INAS (International Association of Sport for Para-athletes with an Intellectual Disability) provides competitive opportunities for highperformance athletes with ID at the international level (Van de Vliet et al., 2006). INAS is an international charity and recognised by International Federation (IOSD) for athletes with an intellectual disability. It is a global organisation that promotes inclusion through sport and is a full member of the International Paralympic Committee representing intellectual disability. INAS was formed in 1986 and has grown to a membership of more than 80 nations across the world, representing more than 130,000 athletes with an intellectual disability (http://www.inas.org/about -us/who-we-are-2/who-we-are). To be able to participate in every four year organized Global Games, the athletes must meet the established qualification or performance standards that involve intense training.

Van de Vliet et al. (2006) examined the physical fitness profiles of elite athletes with ID who participated in the Global Games in 2004 and concluded that in general their fitness levels were, at best equal to, or lower than sporting peers without ID. Temple, Foley, and Lloyd (2014) examined data from the Special Olympics International Health Promotion database and concluded that over 56 percent of Special Olympics participants, especially women and athletes from North America, were overweight and obese.
More specifically, Skowronski, Horvat, Nocera, Roswal, and Croce (2009) were able to delineate variation in physical and motor fitness across a range of ID from mild to severe using the Eurofit Special Test. Their results confirmed what has become the consensus of research going back decades, that is to say, individuals with ID perform at lower levels than their non-ID peers, females function at lower levels than males, and lower functioning is associated with decreasing level of ID.

The purpose of this study was to examine the level of physical fitness of those individuals who participated in Nordic Special Olympics competition 2008 in Finland. Secondly, their fitness level was compared to different values of available adult populations with ID.

\section{Methods}

Participants were 59 athletes (44 men, 15 women) of which 13 had Down syndrome. Data included 44 Finnish and 15 (25.4\%) Swedish athletes who were all men. The mean age was 24.5 (ranging from 16-45). Demographics of the participants are found in Table 1. All participated in the Special Olympics Nordic Games in Finland 2008. They competed in different events such as athletics, swimming, football and floorball.

For comparison to Nordic Special Olympics athletes (Nordic SO-08), our data were compared to two different populations:

1. Global Games 2004 participants who were athletes with ID (INAS-04). The mean age was $22.5 \pm 5.25$ (ranging from 17-49);

2. Sample of individuals (mean age 36.5 , ranging from 34 to 39 years of age) with ID who did not participate in any regular physical activity from the study of Lahtinen et al. (2007) (Finnish ID-96).

Table 1

Demographics of Nordic Special Olympics athletes

\begin{tabular}{|c|c|c|c|c|}
\hline \multirow{3}{*}{ Test } & \multirow[b]{2}{*}{$\begin{array}{c}\text { All } \\
(n=59)\end{array}$} & \multicolumn{2}{|c|}{ Gender } & \multirow{3}{*}{$p$} \\
\hline & & $\begin{array}{l}\text { Women } \\
(n=15)\end{array}$ & $\begin{array}{c}\text { Men } \\
(n=44)\end{array}$ & \\
\hline & $M \pm S D$ & $M \pm S D$ & $M \pm S D$ & \\
\hline Age (years) & $24.5 \pm 7.0$ & $26.3 \pm 7.2$ & $23.9 \pm 7.0$ & .239 \\
\hline Weight (kg) & $71.6 \pm 16.6$ & $67.0 \pm 19.4$ & $73.2 \pm 15.4$ & .060 \\
\hline Height $(\mathrm{cm})$ & $168.0 \pm 10.3$ & $158.2 \pm 7.5$ & $171.3 \pm 9.0$ & $<.001$ \\
\hline
\end{tabular}

Note. $\quad M=$ mean; $S D=$ standard deviation; $p=$ statistical significance. 
To investigate the physical fitness level of the participants, the selected items from Eurofit for Adults ( $\mathrm{Oja}$ \& Tuxworth, 1995) were used. Earlier The Eurofit Test Battery has been found to be reliable with adolescent males with ID (MacDonncha, Watson, McSweeney, \& O'Donovan, 1999). The anthropometric measurements included weight and height. Body mass index (BMI) was defined as body mass ( $\mathrm{kg}$, measured using an electronic weighing scale to the nearest $0.1 \mathrm{~kg}$ ) divided by height ( $\mathrm{m}$, measured to the nearest $0.1 \mathrm{~cm}$ ) squared $\left(\mathrm{kg} / \mathrm{m}^{2}\right)$. The fitness test battery included the following items: sit-and-reach, single leg balance, dynamic sit-up, standing long jump, hand grip, shuttle run and the 1 mile/UKK $2 \mathrm{~km}$ walk test. Flexibility was measured using the sit and reach-test. Participants sat on the floor with straight legs and reached forward as far as possible. The knees were held in extended position by the investigator throughout the reach. The ruler had to be pushed on the bench with a smooth and slow movement. The better of the two trials was recorded to the nearest $1 \mathrm{~cm}$. Whole body balance (stork stand, called leg balance) was measured as the number of trials needed by individuals to achieve a total duration of $30 \mathrm{~s}$ in balance on their preferred foot on a flat firm surface wearing shoes. Abdominal muscle endurance was measured as the number of correctly completed sit-ups in $30 \mathrm{~s}$. Sit-ups were performed with the hands placed at the side of the head, knees bent at $90^{\circ}$, and the feet secured by the investigator. A full sit-up is defined as touching the knees with elbows and returning the shoulders to the ground. Explosive strength was measured by a standing long jump, using a tape measure on a foam mat. Participants were asked to stand behind a line drawn perpendicular to the tape measure and jump forward as far as possible using arm swing and knee bending before jumping. The distance jumped was recorded from the take-off line to the farthest point. The better of two trials was measured to the nearest $0.1 \mathrm{~cm}$. Upper body strength was measured by hand grip dynamometer (Lafayette Instruments) to be squeezed as forcefully as possible with the preferred arm fully extended slightly away from the body, and palm facing inward. The better of two trials was recorded to the nearest $0.1 \mathrm{~kg}$. Running speed was assessed using a 10 times $5 \mathrm{~m}$ shuttle run. Each participant was required to sprint 10 times between two lines placed $5 \mathrm{~m}$ apart. The track was $1.3 \mathrm{~m}$ wide. The sprint was followed by immediately turning and running back. The result was recorded to the nearest tenth of a second. Cardiorespiratory endurance was estimated using a $2 \mathrm{~km}$ walk test (http://www.ukkinstituutti.fi/filebank/1118-UKK_walk_test_testers_guide. pdf) from which the lap time of one mile (1609 m) and $2000 \mathrm{~m}$ was used for comparison.

All participants were invited to take part of the physical tests during the games. Members of the testing crew contacted the team leaders and coaches personally at the competition sites to obtain a random sample of the participants. Coaches accompanied the athletes to the testing. The testing did not interfere with any of the competitions. Informed consent was taken from each participant and/or their legal guardian before the testing began. The study was approved by the Special Olympics Finland.

Descriptive statistics were computed and statistical analyses were carried out using the Statistical Package for Social Science 20.0 (SPSS, Inc., Chicago, IL, USA). Non-parametric analysis (Mann-Whitney U) was used to calculate gender differences. For the comparison of mean values between groups, analysis of variance (ANOVA) and Tukey's HSD (honestly significant difference) test were used. All statistical tests with $p$ values less than .05 were considered significant.

\section{Results}

The test performance means and standard deviations of the Nordic Special Olympics athletes can be found in Table 2. The statistically significant differences between women and men were found in strength (long jump and hand grip), agility (shuttle run), and endurance ( $1 \mathrm{mile} / 2 \mathrm{~km}$ walk), in favour of men.

INAS-athletes (both women and men) exceeded the Nordic Special Olympics athletes significantly in every physical fitness variable, except in flexibility (Table 3). In comparison to non-athletic individuals with ID, the Special Olympics athletes had lower BMI scores, were more flexible, had higher values in hand grip as well as walked faster one mile. The only statistically significant difference was in hand grip, in favor of Special Olympics male athletes. On the other hand, the Special Olympics athletes' sit up scores were statistically significantly lower than those of non-athletic individuals. It is noteworthy that the sit-up tests for Finnish individuals with ID had been performed without the time limit compared to the $30 \mathrm{~s}$ time limit for Special Olympics athletes.

\section{Discussion}

The purpose of the study was to investigate at what level the Nordic Special Olympics athletes are with 
Table 2

Test performances of Nordic Special Olympics athletes

\begin{tabular}{|c|c|c|c|c|}
\hline \multirow{3}{*}{ Test } & \multirow[b]{2}{*}{$\begin{array}{c}\text { All } \\
(n=59)\end{array}$} & \multicolumn{2}{|c|}{ Gender } & \multirow{3}{*}{$p$} \\
\hline & & $\begin{array}{l}\text { Women } \\
(n=15)\end{array}$ & $\begin{array}{c}\text { Men } \\
(n=44)\end{array}$ & \\
\hline & $M \pm S D$ & $M \pm S D$ & $M \pm S D$ & \\
\hline BMI $\left(\mathrm{kg} / \mathrm{m}^{2}\right)$ & $25.3 \pm 5.3$ & $26.8 \pm 7.7$ & $24.8 \pm 4.2$ & .781 \\
\hline Sit and reach $(\mathrm{cm})$ & $31.2 \pm 11.1$ & $33.5 \pm 13.2$ & $30.4 \pm 10.3$ & .384 \\
\hline Leg balance (trials) & $4.2 \pm 7.4$ & $5.1 \pm 7.5$ & $3.9 \pm 7.5$ & .076 \\
\hline Sit-ups (times) & $11.5 \pm 5.7$ & $9.2 \pm 6.7$ & $12.3 \pm 5.2$ & .135 \\
\hline Standing Long Jump (cm) & $142.6 \pm 42.8$ & $107.1 \pm 29.9$ & $154.7 \pm 39.8$ & $<.001$ \\
\hline Hand grip (kg) & $32.3 \pm 11.4$ & $21.2 \pm 4.4$ & $36.1 \pm 10.6$ & $<.001$ \\
\hline Shuttle run (s) & $29.0 \pm 6.9$ & $33.0 \pm 7.1$ & $27.6 \pm 6.8$ & .009 \\
\hline $2 \mathrm{~km}$ walk test (min) & $18.6 \pm 2.8^{3}$ & $21.1 \pm 2.9$ & $18.0 \pm 2.5$ & .003 \\
\hline 1 mile walk (min) & $15.1 \pm 2.6^{4}$ & $17.3 \pm 3.0^{1}$ & $14.4 \pm 2.0^{2}$ & .001 \\
\hline
\end{tabular}

Table 3

Nordic athletes' test performances compared with reference populations

\begin{tabular}{|c|c|c|c|c|c|c|c|c|}
\hline \multirow{3}{*}{ Test } & & & \multicolumn{3}{|c|}{ Men } & & & \\
\hline & \multicolumn{2}{|c|}{$\begin{array}{l}\text { Nordic SO-08 } \\
\quad(n=44)\end{array}$} & \multicolumn{3}{|c|}{$\begin{array}{l}\text { INAS-04 } \\
(n=231)\end{array}$} & \multicolumn{3}{|c|}{$\begin{array}{l}\text { Finnish ID-96 } \\
\qquad(n=37)\end{array}$} \\
\hline & $M \pm S D$ & & $M \pm S D$ & & & $M \pm S D$ & & \\
\hline BMI $\left(\mathrm{kg} / \mathrm{m}^{2}\right)$ & $24.8 \pm 4.2$ & & $23.0 \pm 3.1$ & $(226)$ & $*$ & $27.2 \pm 7.1$ & & \\
\hline Sit and reach $(\mathrm{cm})$ & $30.3 \pm 10.3$ & & $32.1 \pm 9.1$ & $(230)$ & & $29.1 \pm 12.3$ & & \\
\hline Leg balance (trials/30s) & $3.9 \pm 7.5$ & & $1.2 \pm 0.75$ & & $* * *$ & $20.2 \pm 18.2^{1}$ & (35) & $* * *$ \\
\hline Sit-ups (times/30s) & $12.3 \pm 5.2$ & & $25.0 \pm 5.2$ & $(228)$ & $* * *$ & & & \\
\hline Standing Long Jump (cm) & $154.7 \pm 39.8$ & & $210.3 \pm 30.5$ & (229) & $* * *$ & & & \\
\hline Hand grip $(\mathrm{kg})$ & $36.1 \pm 10.6$ & & $41.8 \pm 9.0$ & & $* *$ & $30.4 \pm 10.8$ & $(35)$ & $*$ \\
\hline Shuttle run (s) & $27.6 \pm 6.8$ & & $17.7 \pm 2.2$ & $(225)$ & $* * *$ & & & \\
\hline 1 mile walk (min) & $14.4 \pm 2.0$ & (37) & & & & $16.5 \pm 3.6$ & (32) & $* *$ \\
\hline \multirow{3}{*}{ Test } & & & \multicolumn{3}{|c|}{ Women } & & & \\
\hline & \multicolumn{2}{|c|}{$\begin{array}{l}\text { Nordic SO-08 } \\
\qquad(n=15)\end{array}$} & \multicolumn{3}{|c|}{$\begin{array}{l}\text { INAS-04 } \\
(n=82)\end{array}$} & \multicolumn{3}{|c|}{$\begin{array}{l}\text { Finnish ID-96 } \\
\quad(n=27)\end{array}$} \\
\hline & $M \pm S D$ & & $M \pm S D$ & & & $M \pm S D$ & & \\
\hline BMI $\left(\mathrm{kg} / \mathrm{m}^{2}\right)$ & $26.8 \pm 7.7$ & & $22.5 \pm 3.7$ & & $*$ & $31.4 \pm 9.1$ & & \\
\hline Sit and reach $(\mathrm{cm})$ & $33.5 \pm 13.2$ & & $33.8 \pm 8.3$ & & & $28.8 \pm 9.5$ & & \\
\hline Leg balance (trials/30s) & $5.1 \pm 7.5$ & & $1.5 \pm 2.3$ & $(80)$ & $*$ & & & \\
\hline Sit-ups (times/30s) & $9.2 \pm 6.7$ & & $18.9 \pm 6.4$ & $(81)$ & $* * *$ & $11.1 \pm 9.7^{1}$ & (25) & $* * *$ \\
\hline Standing Long Jump (cm) & $107.1 \pm 29.9$ & & $160.6 \pm 25.4$ & & $* * *$ & & & \\
\hline Hand grip (kg) & $21.2 \pm 4.4$ & & $26.3 \pm 7.0$ & & $*$ & $20.3 \pm 7.0$ & (24) & \\
\hline Shuttle run (s) & $33.0 \pm 7.1$ & & $20.5 \pm 2.7$ & (78) & $* * *$ & & & \\
\hline 1 mile walk (min) & $17.3 \pm 3.0$ & (12) & & & & $18.8 \pm 2.8$ & (20) & \\
\hline
\end{tabular}

Note. $\quad M=$ mean; $S D=$ standard deviation; $\mathrm{SO}=$ Special Olympics; ${ }^{1}$ no time limit; $*$ significance level at $0.05 ; * *$ significance level at $0.01 ; * * *$ significance level at 0.001 . 
their physical fitness. To our knowledge this has not been studied before. It was also interesting to compare this population, with the similar age athletes who presumably train and compete at the higher level (INAS-athletes), and to individuals with ID who do not train and compete on the regular basis. It seemed that the BMI and flexibility values of Special Olympics athletes are very comparable to all the other populations. However, in most of the other fitness parameters which could be compared, Special Olympics athletes fell below the INAS-athletes. On the other hand, their fitness values exceeded the results of 'sedentary' individuals with ID, except in abdominal strength in which the testing procedure was different and did not allow the fair comparison.

Many studies state that individuals with ID have higher prevalence of overweight and obesity than their peers without ID (e.g., Rimmer \& Yamaki, 2006). This applies to Special Olympics athletes as well (Foley, Lloyd, \& Temple, 2013). Women with ID tend to be more overweight or obese than men (e.g., Temple et al., 2014). When compared to men, women seem to have higher BMI values than men also among non-athletes with ID (e.g., Lahtinen et al., 2007). In our study women and men did not differ statistically significantly from each other. Women's BMI was 26.8 which is considered overweight, but men's value was within the ,normal" range. Although the number of women participating in this study was low $(n=15)$, this study does not support the earlier findings of high prevalence of obesity among individuals with ID.

In all of the fitness variables, men in this study overpowered women, except in flexibility and balance. Clear statistically significant difference was found in all other fitness variables except in sit-up results. Surprisingly, among INAS-athletes and Finnish sedentary ID's, men were better in balance than women (Lahtinen et al., 2007; Van de Vliet et al., 2006). In flexibility test, female INAS-athletes as female Special Olympicsathletes scored better than males, but among sedentary individuals the situation was reversed.

INAS-athletes whose amount of training and motivation to compete is presumably higher than among Special Olympics athletes, one would accordingly expect the higher fitness performance. This was indeed the case, only in flexibility the difference was not found statistically significant, but still in favor of INAS-athletes. The study of Frey, McCubbin, Hannigan-Downs, Kasser and Skaggs (1999) supports this scenario, in the sense that when athletes whose goal is to compete in marathons, their peak $\mathrm{VO}_{2}$ values are comparable to other seriously training athletes without disabilities. Unfortunately, we do not know the training history of our sample nor do we know the events in which they most often compete. This is certainly a limitation of the study.

One would assume that Special Olympics athletes perform better than inactive individuals with ID. This was somewhat evidenced in our study, but the difference was not large. In fact, the only statistically significant difference was among men in hand grip strength and one mile walk time. Within women this difference was not detected. This will throw a shadow on the amount of training that actually happens within Special Olympics programs. An interesting finding was that non-athletic Finnish individuals with ID scored better than the Special Olympics athletes but not better than INAS-athletes in abdominal strength. The difference was statistically significant, and therefore surprising in the light of previous literature. However, it could probably be explained by the fact that the sit-up tests for Finnish individuals with ID had been performed without the time limit which may have created the higher score than having a $30 \mathrm{~s}$ time limit of Special Olympics athletes.

As limitations of the study, we will find the following: First, overall the sample sizes were small among Special Olympics athletes and Finnish ID's, especially the number of women. Second, we did not know specifically the sport events of Special Olympics athletes participated in the games, and what they actually trained for. Third, the tests performed in the midst of the games environment may create extra anxiety, stress and fatigue for the athletes and, therefore, may affect their test performances negatively. Fourth, the different number of individuals with Down syndrome within each group decreases the validity of the comparisons.

Down syndrome (DS) is associated among other things with muscle hypotonicity, joint hypermobility, low cardiovascular fitness, and decreased muscle strength already in adolescence (Gonzalez-Aguero et al., 2010). These characteristics will affect their fitness test scores negatively (Pitetti, Rimmer, \& Fernhall, 1993). In our sample there were 13 Special Olympics athletes with DS (22\% of the sample), 17 Finnish individuals with DS ( $26 \%$ of the sample), but none of the INASathletes had DS. When comparing the fitness results among different groups, this puts INAS-athletes in the better position, and creates even the bigger difference in favor of INAS-athletes than it actually is. On the other hand, the similar percentage of DS individuals in the samples Special Olympics athletes and Finnish IDs makes the comparison meaningful. As 
an anecdotal observation, Special Olympics athletes with and without DS were compared. Athletes with DS performed poorer than non-DS athletes in almost all fitness variables, except in flexibility where they surprisingly were not better either. However, no statistical difference was found between these two groups in sit-ups and BMI.

\section{Perspective}

Nordic Special Olympic athletes' physical fitness level fell below the INAS-athletes, except in BMI and flexibility, but was better than those of Finnish non-athletes'. Based on the existing literature and the results of this study, the level of physical fitness of Special Olympic athletes is low and warrants more research. Moreover, the promotion of fitness and physical activity is essential to prolonging a healthy and robust lifestyle into one's later years - well beyond the time when competition has ended. Likewise, a closer examination of the contents of training programs offered in Special Olympics is defensible. Perhaps this level of scrutiny will justify additional training to reach and maintain moderate levels of physical performance in all components of fitness across participants' lifespan.

\section{References}

Barwick, R. B., Tillman, M. D., Stopka, C. B., Dipnarine, K., Delisle, A., \& Huq, M. S. (2012). Physical capacity and functional abilities improve in young adults with intellectual disabilities after functional training. Journal of Strength and Conditioning Research, 26, 1638-1643.

Brooker, K., van Dooren, K., McPherson, L., Lennox, N., \& Ware, R. (2015). Systematic review of interventions aiming to improve involvement in physical activity among adults with intellectual disability. Journal of Physical Activity and Health, 12, 434-444.

Cowley, P. M., Ploutz-Snyder, L. L., Baynard, T., Heffernan, K., Jae, S. Y., Hsu, S., ... Fernhall, B. (2010). Physical fitness predicts functional tasks in individuals with Down syndrome. Medicine \& Science in Sports \& Exercise, 42, 388-393.

Evenhuis, H., Henderson, C. M., Beange, H., Lennox, N., \& Chicoine, B. (2000). Healthy ageing-adults with intellectual disabilities: Physical health issues. Geneva, Switzerland: World Health Organization.

Finlayson, J., Jackson, A., Cooper, S., Morrison, J., Melville, C., Smiley, E., ... Mantry. D. (2009). Understanding predictors of low physical activity in adults with intellectual disabilities. Journal of Applied Research in Intellectual Disabilities, 22, 236-247.

Foster, B. L, Walkley, J. W., \& Temple, V. A. (2001). Bone mineral density status of women with intellectual disability. Adapted Physical Activity Quarterly, 18, 49-59.

Foley, J. T., Lloyd, M., \& Temple, V. A. (2013). Body Mass Index trends among adult United States Special Olympians,
2005-2010. Adapted Physical Activity Quarterly, 30, 373-386.

Frey, G. C., McCubbin, J. A., Hannigan-Downs, S., Kasser, S. L., \& Skaggs, S. O. (1999). Physical fitness of trained runners with and without mild mental retardation. AdaptedPhysical Activity Quarterly, 16(2), 126-137.

Gillespie, M. (2008). Participation patterns in an urban Special Olympics programme. British Journal of Learning Disabilities, 37, 21-27.

Gonzalez-Aguero, A., Vicente-Rodriguez, G., Moreno, L. A., Guerra-Balic, M., Ara, I., \& Casajus, J. A. (2010). Healthrelated physical fitness in children and adolescents with Down syndrome and response to training. Scandinavian Journal of Medicine \& Science in Sports 20, 716-724.

Graham, A., \& Reid, G. (2000). Physical fitness of adults with an intellectual disability: A 13-year follow-up study. Research Quarterly for Exercise and Sport, 71(2), 152-161.

Lahtinen, U., Rintala, P., \& Malin, A. (2007). Physical performance of individuals with intellectual disability: A 30 year follow up. Adapted Physical Activity Quarterly, 24, 125-143.

Lorentzen, B., \& Wikström, B-M. (2012). Healthy lifestyle for people with intellectual disabilities through a health intervention program. Open Journal of Nursing, 2, 157-164.

Mac Donncha, C., Watson, A. W. S., McSweeney, T., \& O'Donovan, D. (1999). Reliability of Eurofit Physical Fitness items for adolescent males with and without mental retardation. Adapted Physical Activity Quarterly, 16, 86-95.

McGuire, B. E., Daly, P., \& Smyth, F. (2007). Lifestyle and health behaviours of adults with an intellectual disability. Journal of Intellectual Disability Research, 51, 497-510.

Messent, P. R., Cooke, C. B., \& Long, J. (1998). Daily physical activity in adults with mild and moderate learning disabilities: Is there enough? Disability and Rehabilitation, 20, 424-427.

Oja, P., \& Tuxworth, B. (Eds.). (1995). Eurofit for adults: A test battery for the assessment ofthe health-related fitness of adults. Strasbourg: Council of Europe, Committee for the Development of Sport.

Pitetti, K. H., Rimmer, J. H., \& Fernhall, B. (1993). Physical fitness and adults with mental retardation. An overview of current research and future directions. Sports Medicine, 16(1), 23-56.

Rimmer, J. H. (2000). Achieving a beneficial fitness: A program and a philosophy in mental retardation: Contemporary issues in health. Washington, DC: American Association on Mental Retardation. .

Rimmer, J. H., \& Yamaki, K. (2006). Obesity and intellectual disability. Mental Retardation and Developmental Disabilities Research Reviews, 12, 22-27.

Skowronski, W., Horvat, M., Nocera, J., Roswal, G., \& Croce, R. (2009). Eurofit special: European fitness battery score variation among individuals with intellectual disabilities. Adapted Physical Activity Quarterly, 26, 54-67.

Temple, V. A., Foley, J. T., \& Lloyd, M. (2014). Body mass index of adults with intellectual disability participating in Special Olympics by world region. Journal of IntellectualDisability Research, 58, 277-284.

Temple, V. A., \& Walkley, J. W. (2007). Perspectives of constraining and enabling factors for health-promoting physical activity by adults with intellectual disability. Journal of Intellectual and Developmental Disability, 32, 28-38. 
Van de Vliet, P., Rintala, P., Frojd, K., Verellen, J., Van Houtte, S., Daly, D. J., Vanlandewijck, Y. C. (2006). Physical fitness profile of elite athletes with intellectual disability. Scandinavian Journal of Medicine \& Science in Sports, 16, 417-425.

\section{Corresponding author}

Pauli Rintala

Email address | pauli.rintala@jyu.fi 